This is a self-archived version of an original article. This version may differ from the original in pagination and typographic details.

Author(s): Laapotti, Tomi; Pennanen, Eveliina

Title: Meetings in the workplace

Year: 2020

Version: Accepted version (Final draft)

Copyright: (c) 2020 Taylor \& Francis

Rights: In Copyright

Rights url: http://rightsstatements.org/page//nC/1.0/?language=en

Please cite the original version:

Laapotti, T., \& Pennanen, E. (2020). Meetings in the workplace. In L. Mikkola, \& M. Valo (Eds.), Workplace Communication (pp. 83-95). Routledge. https://doi.org/10.4324/9780429196881-7 
Workplace Communication

Chapter 7: Meetings in the Workplace

Tomi Laapotti and Eveliina Pennanen 


\begin{abstract}
Meetings are ubiquitous in societies and organizations, and they are often taken for granted. Meetings are a key organizational practice by which organizations are talked into being. They include problem-solving, decision-making, and sensemaking through which organizational goals are achieved. However, meetings are an institution: They have a ritualistic function in the workplace. This chapter widens the everyday conception of meetings by showcasing their role as communicative practices to make things happen in organizations. The chapter specifies the key communicative processes that take place before, during, and after meetings, and points out the features of a good meeting. After building an understanding of the communicative phenomena in meetings, the chapter concludes by offering ways to improve meeting communication and the motivation of participating them.
\end{abstract}




\section{Meetings in the Workplace}

\section{Introduction}

Meetings are ubiquitous in history, societies, and organizations, from nonprofit foundations to start-ups and multinational companies. Meetings are perhaps the most common communication practice in any workplace. Along with their planning, they represent a significant portion of working time, especially for leaders and for all employees in knowledge work. In fact, a significant part of the work in organizations is performed in meetings (Tracy \& Dimock 2004). Meetings require a substantial investment of organizational resources, and, thus, every organization should be interested in the return on investment in meetings.

In popular discourse (e.g., in business magazines and blogs), meetings are often discussed negatively and described as needing improvement. With a quick internet search, it becomes clear that meetings are an easy target for self-help listicles emphasizing the need for improvement. For example, the length, effectiveness, and number of meetings are common topics of complaints. There are also many jokes about meetings and committees. These notions suggest that meetings and especially their possibly inoperative nature draw people's attention (see also Schwartzman 2015). Because meetings have a central status in working life, they are constantly present in workplace discourses and in the media. It is important to recognize the dominant discourses of meetings, as they may reinforce dysfunctional interpretations of communication realities in working life. However, meetings are commonly seen as unproductive (Kello 2015). According to Lehmann-Willenbrock, Rogelberg, Allen, and Kello (2018), the worst evaluations of meetings have shown that about half of all meetings are of poor quality. Furthermore, Allen et al. (2012) found that employees prefer meetings with clear objectives and dislike unproductive meetings where they feel their work- 
related resources are wasted. In fact, it might be the quality of meetings, not meetings per se, that leads to negativity regarding them.

The aim of this chapter is to discuss meetings as a key organizational practice and to showcase their role as communicative practices in the workplace. The chapter specifies the communication processes that take place before, during, and after meetings. After building an understanding of the communicative phenomenon known as a meeting, the chapter concludes by offering ways to improve communication in meetings.

Meetings are common and often taken for granted (Schwartzman 2017). As ubiquitous and age-old communication practices, they also seem to resist change (Schwartzman 2015). It is worthwhile to defamiliarize the familiar (Schwartzman 1989) that is, the meeting itself - and to try to understand its characteristics. This way also effectiveness in meetings can be improved (Scott, Allen, Rogelberg, \& Kello 2015).

\section{What Meetings Are (About)}

Meetings are often a routinized part of working life, so they seldom receive particular consideration in the daily life of the workplace. To gain a comprehensive understanding of what meetings can and cannot do for individuals and for organizations, it is worthwhile investigating what meetings are, and what they are not. Meetings make things happen, and they have the power to influence employees' behavior.

\section{Characteristics of Meetings}

Meetings are an important form of group communication in the workplace. Meetings can refer to a wide range of gatherings - from board meetings to random encounters between coworkers. However, this chapter focuses on scheduled or otherwise appointed workplace or organizational meetings, involving many people and taking place in private, public, or third sector organizations. These kinds of meetings can exhibit different degrees of formality and representativeness, but they all are task-focused. Meetings can be informal weekly get- 
togethers where topical issues are discussed with colleagues without a chair or secretary (e.g., informal team meetings). Alternatively, they can follow a strict agenda, according to which a chair gives permission to speak and the minutes must be reported to other levels of the organization (e.g., board meetings). Although meetings are prepared and scheduled, they may lack time limits or formal agendas. They can be required and organized by the organization, management, or leaders, or they can be created by peer coworkers in everyday work interactions. They can be carried out face-to-face or by means of communication technology. The goals and forms of meetings, as well as the need for them, are as manifold as contemporary working life itself.

Meetings are often representative, sometimes explicitly and sometimes implicitly. Employees in meetings usually represent not only themselves but also their department, peer coworkers, project, area of responsibility, profession, and so forth. Power dynamics sometimes complicate the representativeness, especially when the question of who has the right to represent whom must be addressed (Kendall \& Silver 2017). For example, in explicitly representative meetings, if the representatives of staff do not have actual administrative roles, their level of participation may remain low (Laapotti \& Mikkola 2016).

\section{Types and Purposes of Meetings}

In the workplace, meetings come in many types, and they also have a variety of purposes. Board meetings, management team meetings, staff meetings, departmental meetings, team meetings, and informal meetings are common types of meetings. Scott et al. (2015) explored metaphors often used to describe meetings: Stressors, collaboration technology, rituals, sensemaking, or interventions. Those metaphors indicate the many purposes of meetings: Sharing information, making decisions, solving problems, supporting management, innovating, sharing tasks, giving feedback, strengthening collaboration and organizational values, and so on. The type and purpose of the meeting are important 
dimensions when evaluating and developing meetings. Even though there are many features that are common to all meetings, meetings cannot be treated as all being the same. When developing them, any solutions cannot be offered without taking contextual factors into account.

The relational level of meetings should be acknowledged. The motivation and satisfaction of employees are constructed both in task-related and relational communication. Meetings are particularly important venues for building the relational side of organizational life. Consequently, the investment in developing meeting interactions is beneficial not only for better task performance but also for the employees' satisfaction and well-being. Meetings provide opportunities for employees to engage in talk - also small talk - about organizational and workplace issues. Such meeting talk makes the organization real for the participants. When meeting talk engages and positions the participants, it becomes appreciated, official, and influential.

Meetings are at the core of all crucial organizational processes, from management to decision-making (Boden 1994; Schwartzman 1989). Meetings are always more or less about power, and they are central to many management models (Boden 1994; Thedvall 2017). The most important strategic work in organizations takes place during meetings (e.g., Clarke, Kwon, \& Wodak 2012). Essential managerial actions are performed in meetings, decisions are made or legitimized, and valuable information is shared. Meetings are miniature versions of organizations, and in them employees can position themselves as part of the organization. From this point of view, organizations do not produce meetings, but rather meetings produce organizations (Schwartzman 1989). Meetings have a key role in constituting the organization. In other words, organizations are constructed in workplace interaction (i.e., talked into being outside everyday experiences), and meetings are a distinct form of communication involved in this construction. 
According to Boden (1994), organizations maintain and reorganize themselves through interactions in meetings. It is communication in meetings that brings to light organizational structures such as hierarchies, makes organizational processes such as decision-making explicit, reflects past actions, and coordinates future ones. Thus, in meetings, organizations are made visible symbolically, and participants express their opinions, legitimize their roles, and coordinate their working time and space (ibid.). Meetings are first and foremost communication, and the key to understanding the importance of meetings and improving them therefore lies in communication.

\section{Meetings as an Institution}

Meetings exist everywhere, and they have similar characteristics in different contexts, irrespective of their goals (Schwartzman 1989; Van Vree 2011). Meetings themselves are institutions. Institutions extend beyond particular organizations because they consist of rather fixed and continuing beliefs, behaviors, rules, and practices (Lammers \& Barbour 2006). There are certain established aspects that are repeated in the same way from one organization to another. For instance, meetings often reflect the demands and expectations regarding certain positions (e.g., leader, employee, trainee), and the fixed beliefs may be repeated in the same way in different workplaces (ibid.).

Meetings are crucial occasions in which the organization is constituted. However, meetings are institutions in themselves, certainly affected by the elements of the organization in which they are embedded. The organizational structures are known to guide people's behavior rather extensively (e.g., McPhee, Poole, \& Iverson 2014). Consequently, like all communication situations, meetings involve more than they seemingly would appear. If, for example, the effectiveness of decision-making in meetings needs to be improved, it may be insufficient to focus only on the meeting or its planning. Sometimes it is not the meeting that needs to be changed for the better but broader organizational issues. Understanding the full 
value of meetings for the organization helps to evaluate the actual need for development more thoroughly.

Meetings are legitimized and stable nodes in organizational life. They are therefore key occasions for the organization (Bargiela-Chiappini \& Harris 1997). The legitimacy and stability of meetings are partly due to their recurrent nature. Through their institutional characteristics, meetings represent stability. This becomes evident in rather formal weekly or monthly meetings, which often resemble one another. The ritualistic and even ceremonial nature of meetings come alive in them: they are usually performed in a fairly similar manner, regardless of the topics discussed. The execution of ritualistic meeting practices and routines, such as writing minutes and chairing, are known to enhance the credibility of meetings and the groups conducting them (Abram 2017; Schwartzman 1989). Thus, it is not surprising that it is difficult for meetings to evolve.

Nevertheless, meetings can also represent change because they are intimately connected to the constitution, producing, and reproducing of organizations. Naturally, both stabilizing and change-oriented meetings are needed in organizations. Schwartzman (2015; 2017) states that meetings are not always about order and stability; that is, meetings not only create social order, they also break it. Meetings can create chaos or block important reforms in organizations. Of course, meetings can also be the awakening force that brings out the latent need for reforms.

\section{Interactions in Meetings}

Communication is the key to understanding the quality of meetings. Whether they take the form of face-to-face or technology-mediated interaction, meetings exhibit many recognizable communication practices and structures. An organization can examine them in order to improve the effectiveness of its meetings. Ultimately, it is the interactions that take place in meetings that define how meetings are perceived. 


\section{Communication Practices in Meetings}

Meetings are arranged and held to advance operations and to promote issues regarded as important in the workplace. Meetings often make a difference within their environments and within the lives of participants, and as such they have an important effect on the organizing process and especially on the stability of the organization (Cooren \& Fairhurst 2009; Duffy 2016). All this happens communicatively, and it is therefore important to understand the value and importance of the communication behavior in meetings.

In meetings, many established communication practices have an effect on the behaviors of the participants. These practices include chairing, formal turn-taking, recording minutes, and setting the agenda. The practices are connected to the participation and involvement of leaders and peer coworkers, to issues of power, to interpersonal relationships, and to the discussion of topics that takes place in the meeting. These aspects become visible in communication behavior: Who is chairing, who is taking minutes, how speaking turns are distributed, whose participation is seen as relevant and whose is not, and what kinds of discussion topics are favored.

The organization can define - either explicitly or implicitly - what kinds of communication practices and meeting behavior are desirable. The social interaction that takes place in meetings is based not only on the characteristics of specific groups in the workplace or individual employees but also on the institutional aspects of meetings (information sharing, chairing, turn-taking, representativeness) and of organizational hierarchies (Laapotti \& Mikkola 2016).

Furthermore, because of their institutional nature, meetings are well respected, and as a result of their communicative structure, they have a considerable effect on the participants' behaviors. For example, if a certain issue needs to be mentioned and written down in the formal meeting minutes, the issue is raised in the meeting's discussion only for this reason. In 
these kinds of situations, the participants may behave as though the issue at hand is new, even though they are all familiar with it (Laapotti \& Mikkola in press). This kind of meeting ritual may sometimes result in frustration. In order to improve the effectiveness of meetings, it is important to become aware of the different functions and roles the meetings are playing.

Thus, evaluating the meeting as it is happening - and especially the usual communication practices in them - can be an effective way to improve both the task-level outcomes and perceived satisfaction. For example, the structures of communication processes can reveal how organizational hierarchies limit the discussion during meetings (Laapotti \& Mikkola 2016). Recognizing this can help to ensure that everyone gets to participate and that processes such as decision-making are participatory. These are characteristics of successful meetings (Lehmann-Willenbrock et al. 2018).

Communication is the key determinant of the success or failure of meetings; it defines their quality. As communicative events, meetings are occasions that connect local interactions of employees to organization-level discourses. Participants of meetings position both themselves and their work within the organization as a whole. These processes both integrate and reinforce the differences among various viewpoints (Schwartzman 2017; Yarrow 2017). Meeting interactions are related to the success of both the groups that convene in meetings and the organization in which the meetings take place (Kauffeld \& LehmannWillenbrock 2012).

\section{Communication in Meetings}

Communication in meetings is often mostly task-oriented. However, the relational level - for instance, showing friendliness and joking together - is highly important for creating cohesion, which also facilitates the achievement of the task-oriented goals. In addition, pre- and post-meeting communication is relevant. It has been shown that positive 
pre-meeting small talk has a strong effect on meeting effectiveness (Allen, LehmannWillenbrock, \& Landowski 2014).

Additionally, responsibility - the relational and attributional construct in which one party is accountable to another - is communicatively created in meetings (Lenk 2003). For instance, co-responsibility or individual responsibility concerning tasks and duties (e.g., who takes care of what on a certain project) or non-responsibility (e.g., shifting responsibility by representing oneself only as a messenger and not a decision-maker) is created in the communicative processes of meetings (Pennanen \& Mikkola 2018). Furthermore, in meetings, the participants position themselves as part of the surrounding organization, construct the feeling of belongingness, and make sense of the organization as a whole (Laapotti \& Mikkola 2016).

Communication in meetings has a crucial effect on meeting satisfaction and productivity (Malouff, Calic, McGrory, Murrell, \& Schutte 2012). Appropriate participant behavior includes:

- $\quad$ being on time;

- $\quad$ speaking in a concise matter;

- $\quad$ advancing the meeting agenda;

- $\quad$ encouraging others to participate;

- $\quad$ aiming for solution;

- $\quad$ paraphrasing;

- $\quad$ being positive about the organization's future;

- $\quad$ and recapitulating the decisions made.

Clarifying the purpose of the topic is of vital importance, because not all meeting talk is solution-oriented. Topics are and they should be approached differently whether they are on the agenda for information, for discussion, or for decision-making. The conversation for 
each purpose has a different function, and understanding the goal of conversation in a current situation increases the quality of meeting interaction. Being aware of the interaction task at hand also promotes the effectiveness of the meeting.

Problem-solving is one of the most important communication tasks. It is an organizational process evident in meetings, and it is often directly related to organizational decision-making. It is frequently in meeting interactions that a problem is identified, or information concerning a problem is provided to managers or leaders. To solve a problem, it must be recognized or articulated, and the people responsible for addressing it must be identified (Angouri \& Bargiela-Chiappini 2011). In contemporary organizations, problems can be complex and sometimes even unsolvable (i.e., they need to be managed or coped with, rather than conclusively solved). Meetings are important occasions for making sense of these kinds of problems. To address complex problems, it is important to build a shared understanding of them. Such sensemaking can support the overall problem-solving process at the level of the organization as a whole, and it can help meeting participants manage the problem at hand (Laapotti \& Mikkola, in press). Thus, discussions of problems in meetings can be an important asset for organizations, even when such discussions seem ineffective at the level of an individual meeting.

The same goes for many other important organizational processes: Evaluating only one meeting does not say much about the productiveness of meetings in general. Therefore, meetings should be evaluated as a systemic whole within an organization; that is, their effectiveness with respect to broad organizational processes or issues should be assessed (Duffy \& O'Rourke 2015).

The chair is often seen as being responsible for the meeting. Successful chairing compounds the following strategies

- $\quad$ motivating the participants; 
- $\quad$ encouraging appropriate participation;

- $\quad$ directing the discussion toward solutions;

- $\quad$ modulating between encouraging and directing strategies;

- $\quad$ and committing the participants to implementing the decisions made in the meeting (Wodak, Kwon \& Clarke 2011).

A skillful chair also keeps the focus on the task at hand and ensures that everyone gets an opportunity to participate and speak their minds. However, the chair is not solely responsible for successful meetings. For example, the facilitating of procedural communication by all participants has positive effects on achieving the goals of the meeting (Lehmann-Willenbrock, Allen, \& Kauffeld 2013). It is everyone's responsibility, not just the chair's, to express procedural statements during meetings.

Communication in meetings has often its own characteristics in the workplace. Usually the communication is rather formal, at least compared to the talk before and after meetings (Nielsen 2013). Communication in meetings is often multimodal due to the presence of different kinds of documents, such as the meeting agenda, and visualization devices, such as whiteboards (Svennevig 2012). Many meetings in working life are, completely or partly, technology-mediated. When the participants are not physically present in the same room, some communicative features must be carefully taken into account. For instance, the expressions of presence or absence require some extra attention in technologymediated meetings (see Sivunen 2016).

\section{Meeting Satisfaction}

Meeting satisfaction is connected to overall job satisfaction (Rogelberg, Allen, Shanock, Scott, \& Shuffler 2010). The feeling of being able to execute one's agency seems to enhance meeting satisfaction, and this feeling can be achieved also if the meeting communication is perceived as good by the participants (Laapotti \& Mikkola 2016). 
Meetings are not only task-oriented gatherings, but they enable the participants to define their relationships (Beck \& Keyton 2009). For example, social solidarity is constructed during meetings, which makes them important regardless of whether the goals are achieved or not (Peck, 6, Gulliver \& Towell 2004).

Lehmann-Willenbrock et al. (2018) identified certain elements that characterize good meetings. Good meetings start and end on time, and they have clear goals, a written agenda, and relevant participants. Time to socialize before and after meetings also has a positive effect. The communication should be related to encouraging participation, building consensus, and focusing on solutions.

Furthermore, all participants' opinions should be heard, and decision-making should be inclusive. Encouraging positive communication, elaborating on other participants' ideas, and discouraging negative cycles (e.g., complaining) are significant features of successful meetings. Information should be shared openly, and concrete plans for future actions should be explicated. Moreover, meeting minutes are important for achieving good results. Good meetings result in employees' satisfaction, creativity, engagement, well-being, and empowerment. At team and organizational levels they result in good performance, productivity, and development (ibid.).

\section{Practical Implications}

In meetings, the past, current, and future events or processes of the organization are discussed and made sense of. This constitutes a shared social reality and makes the organization real for the participants outside of their everyday work (Laapotti \& Mikkola 2016). The way the organization is discussed during meetings revises past events and enables (or restricts) future events. This is why all organizations should be interested in their meetings. They are very special kinds of events, and the talk that takes place in meetings gains its meaningfulness because it happens there and not anywhere else. 
Because meetings epitomize organizations, they can be viewed as indicators of the state of the organization. At the same time, because meetings constitute the organization, improving them can support the improvement of the organization's functions more generally. In other words, focusing on meeting communication can have organization-wide effects (e.g., Weick 1995).

However, focusing only on the meeting situation itself can sometimes result in a merely partial solution when improving meetings in the workplace. Making changes elsewhere in the workplace can improve meetings. If treated as self-contained entities detached from their environment, meetings remain a challenging target for improvement. For example, if there are wider organizational problems with interpersonal relationships, it is unlikely that improvements in the way meetings are performed can help.

Workplace meetings can be improved by focusing on both the communicative practices of the meetings and the sine qua non of the interactions in meetings. Meetings should be evaluated by the participants on a regular basis. An organization can become aware of how its meetings are perceived by asking participants to complete a simple questionnaire. If the participants are dissatisfied, it is important to find out the reasons. Does the dissatisfaction stem from attitude problems or, for example, the types or goals of meetings, or communication practices during meetings? It is important to evaluate also the communication behavior in meetings. Being aware of the characteristics of successful meetings can help to form questions for evaluating the communication: How do we encourage or discourage participation? Do we focus on solutions? If new ideas, critical opinions, or certain emotions expressed in meetings often elicit a negative response or no response at all, people will not feel motivated to participate in them.

If the purpose or the subject of a meeting is irrelevant to the participants, they are not motivated to take part in it. This is particularly problematic for employees whose roles do not 
include any actual responsibilities or opportunities to make a difference. Thus, it is important to define a goal for every meeting. Constructing a shared understanding of the purpose of meetings is the best way to perceive them. Furthermore, it is important to make sure that all participants are familiar with the goals of a particular meeting. The first question to discuss with the participants is: Why are we here? Next, the goals should be examined more thoroughly: Are the goals similar for all participants? Are they fixed, dynamic, realistic? The designated goals may sometimes be impossible to achieve during the meeting, which may cause frustration. If the goal is to make decisions but the issues are too complex to be decided, or if the group does not have the formal power needed for decision-making, a decision cannot be made. However, the group can build important shared meanings and enhance the decision-making in the bigger organizational picture (Laapotti \& Mikkola, in press).

It may be difficult to define the most relevant participants for meetings beforehand. The solution is often to just invite the employees who are predicted to provide the best value for the meeting. Individual differences count, too. Not everyone is equally interested in participating or contributing to the tasks on the agenda, even when the tasks comes under the participant's job description or area of expertise. This is good to keep in mind when feeling frustrated or unsure of one's own role in a meeting.

On the other hand, meetings are not always necessary, and to arrange a meeting just for the sake of holding a meeting is not rational. Many issues can be more efficiently taken care of in dyadic discussions or in emails, for example. When thinking of arranging a meeting, one should consider if there really are enough issues on the agenda or if the issues at hand truly require shared time and input from many people. Meetings are always an investment of resources. 
When recognizing the profoundly important role of meetings and the organizing role of meeting communication, the actual need to improve them has to be carefully considered. Often meetings are perceived as sufficiently good in the workplace, at least if they seem to advance key organizational processes. In some cases, defining and even changing the goals of meetings to match what is actually done in them may enhance a positive change in attitudes toward meetings and, therefore, ultimately improve meetings. The path to this kind of change is meta-discussion: the meeting and its purpose can be discussed before, during, or after the meeting. Also, communication practitioner can help to observe meetings and discerning about what is actually done in the communication processes during meetings.

Meetings are connected to all crucial organizational processes, including the performance of everyday tasks, management and leadership, decision-making, and coordination of work. Meetings constitute the organization through communication; therefore, meetings must be explored from the communication point of view. The whole workplace should be interested in meetings, for example, how they are perceived and how they can be improved.

\section{What to Consider in the Workplace}

- It is important to evaluate meetings regularly. The evaluation is not a project but rather a dynamic, ongoing process that helps the workplace improve over time. Meeting satisfaction should be measured as frequently as customer satisfaction. The types, goals, and the communication in meetings should be evaluated.

- All participants should be aware of the goals of the meetings. One of the best ways to avoid frustrated participants is to crystallize the goals of the meeting. Informing the participants in advance about the goals and agenda helps them to become oriented to the meeting and motivated to attend it. In addition, clear meeting goals help the participants reflect on their own goals. The crucial issues 
of reflection for each participant include one's role, purpose of participation, and the possible contribution to the achievement of the objectives.

- Observation of meeting communication helps in developing the meeting procedures in the workplace. Communication during the meeting should support the pursuing of the goals. It is often beneficial to observe issues of dominance, participation, and involvement. Not everyone is as eager to participate, and the amount of talking is not the only way to measure equal participation. For some participants, it may be significant just to feel that they have an opportunity to participate, even if they do not take advantage of it. Furthermore, communication should be mainly goal- and process-oriented, but relational communication should not be inhibited.

- It is often difficult to evaluate one's own communication behavior and the communication of one's own team in a realistic way, simply because these are routine parts of the everyday practice. Communication practitioners and facilitators can help to see the critical points and ask the relevant questions. Self-evaluation is an excellent starting point for improving meeting communication, but to achieve a more in-depth understanding, outside help is needed.

- Meetings are the most important arenas in which the organization is talked into being. The way we talk about meetings gives rise to the way we think about them. Highlighting the central nature of meetings in organizational life helps us to see their significance in the context of the bigger picture. To simplify, the purpose of meetings is not only to coordinate work or achieve task goals, but also to make the organization what it is and what we would like it to be. 


\section{References}

Abram, S. 2017. Contradiction in contemporary political life: Meeting bureaucracy in Norwegian municipal government. In H. Brown, A. Reed, \& T. Yarrow (Eds) Meetings: Ethnographies of organizational process, bureaucracy, and assembly [special issue]. Journal of the Royal Anthropological Institute 23 (S1), 27-44.

Allen, J. A., Lehmann-Willenbrock, N. \& Landowski, N. 2014. Linking pre-meeting communication to meeting effectiveness. Journal of Managerial Psychology 29(8), $1064-1081$.

Allen, J. A., Sands, S. J., Mueller, S. L., Frear, K. A., Mudd, M. \& Rogelberg, S. G. 2012. Employees' feelings about more meetings: An overt analysis and recommendations for improving meetings. Management Research Review 35(5), 405-418.

Bargiela-Chiappini, F. \& Harris, S. 1997. Managing language: The discourse of corporate meetings. Amsterdam: John Benjamins Publishing Company.

Beck, S. J. \& Keyton, J. 2009. Perceiving strategic meeting interaction. Small Group Research 40(2), 223-246.

Boden, D. 1994. The business of talk: Organization in action. Cambridge: Polity Press.

Clarke, I., Kwon, W. \& Wodak, R. 2012. A context-sensitive approach to analysing talk in strategy meetings. British Journal of Management 23(4), 455-473.

Cooren, F. \& Fairhurst, G. 2009. Dislocation and stabilization: How to scale up from interactions to organization. In L. L. Putnam \& A. M. Nicotera (Eds) Building theories of organization: The constitutive role of communication. New York: Routledge, 117-152.

Duffy, M. 2016. The agency of meetings as systemic process in the constitution of organizations: Insights from a longitudinal study and bifocal analysis of an organization's meetings. Doctoral thesis. Dublin Institute of Technology. 
Kauffeld, S. \& Lehmann-Willenbrock, N. 2012. Meetings matter: Effects of team meetings on team and organizational success. Small Group Research 43(2), 130-158.

Kello, J. E. 2015. The science and practice of workplace meetings. In J. A. Allen, N. Lehmann-Willenbrock \& S. G. Rogelberg (Eds) The Cambridge handbook of meeting science. New York: Cambridge University Press, 709-734.

Kendall, N. \& Silver, R. 2017. Mapping international development relations through meeting technology. In J. Sandler \& R. Thedvall (Eds) Meeting ethnography: Meetings as key technologies of contemporary governance, development, and resistance. New York: Routledge, 24-45.

Laapotti, T. \& Mikkola, L. 2016. Social interaction in management group meetings: A case study of Finnish hospital. Journal of Health Organization and Management 30(4), $613-629$.

Laapotti, T. \& Mikkola, L. In press. Problem talk in management group meetings. Small Group Research.

Lammers, J. C. \& Barbour, J. B. 2006. An institutional theory of organizational communication. Communication Theory 16(3), 356-377.

Lehmann-Willenbrock, N., Allen, J. A. \& Kauffeld, S. 2013. A sequential analysis of procedural meeting communication: How teams facilitate their meetings. Journal of Applied Communication Research 41(4), 365-388.

Lehmann-Willenbrock, N., Rogelberg, S. G., Allen, J. A. \& Kello, J. E. 2018. The critical importance of meetings to leader and organizational success: Evidence-based insights and implications for key stakeholders. Organizational Dynamics 47(1), 32-36.

Lenk, H. 2003. Responsibility for safety and risk minimization: Outline of an attributionbased approach regarding modern technological and societal systems. Human Factors \& Ergonomics in Manufacturing 13(2), 203-222. 
Malouff, J. M., Calic, A., McGrory, C. M., Murrell, R. L. \& Schutte, N. S. 2012. Evidence for a needs-based model of organizational-meeting leadership. Current Psychology 31(1), 35-48.

McPhee, R. D., Poole, M. S. \& Iverson, J. 2014. Structuration theory. In L. L. Putnam \& D. K. Mumby (Eds) Sage handbook of organizational communication: Advances in theory, research, and methods. Thousand Oaks, CA: Sage, 75-100.

Nielsen, M. F. 2013. "Stepping stones" in opening and closing department meetings. Journal of Business Communication 50(1), 34-67.

Peck, E., 6, P., Gulliver, P. \& Towell, D. 2004. Why do we keep on meeting like this? The board as ritual in health and social care. Health Services Management Research 17(2), $100-109$.

Pennanen, E. \& Mikkola, L. 2016. Work coordination as a social interaction process in nursing staff meetings. Nordic Journal of Working Life Studies 6(2), 23-41.

Pennanen, E. \& Mikkola, L. 2018. Constructing responsibility in social interaction: an analysis of responsibility talk in hospital administrative groups. Qualitative Research in Medicine \& Healthcare 2(3), 154-164.

Rogelberg, S. G., Allen, J. A., Shanock, L., Scott, C. \& Shuffler, M. 2010. Employee satisfaction with meetings: A contemporary facet of job satisfaction. Human Resource Management 49(2), 149-172.

Schwartzman, H. B. 1989. The meeting: Gatherings in organizations and communities. New York: Plenum Press.

Schwartzman, H. B. 2015. There's something about meetings: The order and disorder in the study of meetings. In J. A. Allen, N. Lehmann-Willenbrock \& S. G. Rogelberg (Eds) The Cambridge handbook of meeting science. New York: Cambridge University Press, 735-745. 
Schwartzman, H. B. 2017. Conclusion: The meeting and the mirror. In J. Sandler \& R. Thedvall (Eds) Meeting ethnography: Meetings as key technologies of contemporary governance, development, and resistance. New York: Routledge, 158-178.

Scott, C., Allen, J. A., Rogelberg, S. G. \& Kello, A. 2015. Five theoretical lenses for conceptualizing the role of meetings in organizational life. In J. A. Allen, N.

Lehmann-Willenbrock \& S. G. Rogelberg (Eds) The Cambridge handbook of meeting science. New York: Cambridge University Press, 20-46.

Sivunen, A. 2016. Presence and absence in global virtual team meetings: Physical, virtual, and social dimensions. In J. Webster \& K. Randle (Eds) Virtual workers and the global labour market. Basingstoke: Palgrave Macmillan, 199-217.

Svennevig, J. 2012. Interaction in workplace meetings. Discourse Studies 14(1), 3-10.

Thedvall, R. 2017. Meeting to improve: Lean[ing] Swedish public preschools. In J. Sandler \& R. Thedvall (Eds) Meeting ethnography: Meetings as key technologies of contemporary governance, development, and resistance. New York: Routledge, 143157.

Tracy, K. \& Dimock, A. 2004. Meetings: Discursive sites for building and fragmenting community. In P. J. Kalbfleisch (Ed) Communication yearbook 28. Mahwah, NJ: Lawrence Erlbaum, 127-165.

Van Vree, W. 2011. Meetings: The frontline of civilization. Sociological Review 59(1), 241262.

Weick, K. E. 1995. Sensemaking in organizations. Thousand Oaks, CA: Sage.

Wodak, R., Kwon, W. \& Clarke, I. 2011. "Getting people on board”: Discursive leadership for consensus building in team meetings. Discourse \& Society 22(5), 592-644.

Yarrow, T. 2017. Where knowledge meets: Heritage expertise at the intersection of people, perspective, and place. In H. Brown, A. Reed \& T. Yarrow (Eds) Meetings: 
Ethnographies of organizational process, bureaucracy, and assembly [special issue]. Journal of the Royal Anthropological Institute 23 (S1), 95-109. 